\title{
Assessment of optimal growth conditions for specific carotenoids production by Chlorella vulgaris
}

\author{
Saroj Yadav \\ Research and Development Centre, Bharathiar University, Coimbatore (Tamil Nadu), India \\ Sonu Bansal \\ Department of Biotechnology, Indian Academy Degree College-Autonomous, Bangalore \\ (Karnataka), India \\ Chaithra, M. L. \\ Department of Biotechnology, Indian Academy Degree College-Autonomous, Bangalore \\ (Karnataka), India \\ Sibi G.* \\ Department of Biotechnology, Indian Academy Degree College- Autonomous, Bangalore \\ (Karnataka), India \\ *Corresponding Author. Email: gsibii@gmail.com
}

\section{Article Info}

https://doi.org/10.31018/

jans.v12i4.2399

Received: October 6, 2020

Revised: November 17, 2020

Accepted: November 21, 2020

\section{How to Cite}

Yadav S. et al. (2020). Assessment of optimal growth conditions for specific carotenoids production by Chlorella vulgaris. Journal of Applied and Natural Science, 12(4): 550 - 555. https://doi.org/10.31018/jans.v12i4.2399

\begin{abstract}
Exploration of regional microalgae for carotenoids production under optimized cultural conditions is a sustainable economic and technical perspective. This study details comprehensive research on the influence of growth conditions on microalgal carotenoids. Carotenoid triggering factors were optimized to identify suitable growth conditions to produce specific carotenoids by Chlorella vulgaris. Media optimization and cultivation conditions were the factors considered and the results revealed the optimum growth conditions for carotenoid production by $C$. vulgaris was $\mathrm{pH} 8,35^{\circ} \mathrm{C}$ temperature, $0.04 \mathrm{M}$ salinity and $160 \mu \mathrm{E} / \mathrm{m}^{2} \mathrm{lsec}$ light intensity. Among the nutrient sources, potassium nitrate and potassium phosphate were suitable for nitrogen and phosphorous supplements. The results indicated optimizing the culture conditions and nutrient sources help to attain desirable carotenoid production by $C$. vulgaris. Specific carotenoids were extracted from the algal extract and were identified by highperformance liquid chromatography in which lutein (8.8\%) was present as major carotenoid followed by astaxanthin (4.6\%) and $\beta$-carotene $(3.9 \%)$. This study revealed that that carotenoid production by $C$. vulgaris could be enhanced by manipulating culture conditions thereby attain desirable carotenoid production.
\end{abstract}

Keywords: Astaxanthin, $\beta$-carotene, Chlorella vulgaris, Carotenoids, Lutein

\section{INTRODUCTION}

Carotenoids are naturally occurring pigments which have been attributed in the prevention of cardiovascular, neurodegenerative and inflammatory diseases (Chuyen and Eun, 2017; Raposo et al., 2015). Among the photosynthetic organisms, microalgae are the richest producers of carotenoids. Some of the carotenoids such as astaxanthin are rarely found in other organisms which makes microalgae as a versatile source of carotenoids. Microalgae accumulate carotenoids to harvest light, regulate photo protecting process and stabilizing the structure of photosynthetic pigmentprotein complexes (Mimuro and Akimoto, 2003; Mulders et al., 2014). Some microalgae have the ability to produce carotenoids under unfavourable conditions. However, the carotenoid production by microalgae is low under native environmental conditions and it varies between species. There are two possible ways to recover carotenoid from microalgae. One being the favouring of carotenoid production by facilitating the growth environment and another way of doing is adapting a suitable recovery process. Extraction of carotenoid from microorganisms by breaking down the cell membranes and isolation is a crucial step in the recovery process.

Among the various carotenoids produced by microalgae, $\beta$-carotene, astaxanthin and lutein have the highest market potential. $\beta$-carotene is related to provitamin A supply and colouring agent with industrial importance. Astaxanthin has antioxidant potential and anti-inflammatory effects, thereby benefitting human health (Li et al., 2011; Guerin et al. 2003). Lutein is the predominant pigment in the macula and plays a significant role in eye health (Manayi et al., 2015). Lutein 
has been widely used for the pigmentation of various products (Shi and Chen, 1997). Carotenoids extracted from Chlorella species inhibited cancer cells (Cha et al., 2008). Considering the abundancy and multipotential nature, this study focused on Chlorella vulgaris to evaluate its ability to produce carotenoids. To achieve the objective, this study focused on triggering factors influencing carotenoids produced by C. vulgaris. Media optimization and cultivation conditions were the factors considered, and the results were compared with previously reported literature to consider the present results as fruitful findings to apply in commercial production.

\section{MATERIALS AND METHODS}

Algae strain: C. vulgaris isolated from the sewerage treatment plant in the previous study (Mokashi et al., 2016) was cultured in flat panel photobioreactor with a working volume of 5 litres. The culture medium was modified Bold's basal medium with an initial cell density of $30 \times 10^{5}$ per $\mathrm{ml}$.

Chemicals: Methanol, methyl tert-butyl ether (MTBE), ethanol and $\beta$-carotene were obtained from SigmaAldrich (India).

Growth conditions for carotenoid production: Carotenoid production by $C$. vulgaris was optimized by varying $\mathrm{pH}(5,6,7,8$ and 9$)$, temperature $\left(25^{\circ}, 30^{\circ}\right.$, $35^{\circ}, 40^{\circ}$ and $\left.45^{\circ} \mathrm{C}\right)$, nitrogen sources $\left(\mathrm{NaNO}_{3}, \mathrm{KNO}_{3}\right.$, Urea; 3-48 mM), and phosphate $\left(\mathrm{K}_{2} \mathrm{HPO}_{4} ; \mathrm{KH}_{2} \mathrm{PO}_{4}\right.$, $\mathrm{Ca}_{3}\left(\mathrm{PO}_{4}\right)_{2}$ 0.4-6.4 mM) sources, salinity (0.04-0.64 $\mathrm{mM})$ of selected medium and by changing the intensity of light (50 -300 $\left.\mu \mathrm{E} \backslash \mathrm{m}^{2} \backslash \mathrm{sec}\right)$.

Extraction and quantification of carotenoids: Total carotenoids from the microalgae were estimated by centrifuging the cells at $5000 \times \mathrm{g}$ for 10 mins followed by dissolving the pellet in acetone $(20 \mathrm{ml})$. The solvent biomass mixture was incubated at $50^{\circ} \mathrm{C}$ in a water bath for 2 hrs followed by centrifugation at 5000x $\mathrm{g}$. The absorbance of the supernatant was read at 660 , 645 and $470 \mathrm{~nm}$ using UV-Vis spectrophotometer and the total carotenoids content were determined using following equations (Eq.1, Eq.2 and Eq.3) (Lichtenthaler and Buschmann, 2001).

Chlorophyll a $\left(\mu \mathrm{g} / \mathrm{ml}^{-1}\right)=\left(11.24 \mathrm{~A}_{660}\right)-\left(2.04 \mathrm{~A}_{645}\right)$

$$
\begin{aligned}
& \text { Chlorophyll b }\left(\mu \mathrm{g} / \mathrm{ml}^{-1}\right)=\left(20.13 \mathrm{~A}_{645}\right)-\left(4.19 \mathrm{~A}_{660}\right) \\
& \ldots \ldots .(\mathrm{Eq} .2) \\
& \begin{array}{c}
\text { Carotenoids } \\
\left(\mu \mathrm{g} / \mathrm{ml}^{-1}\right)
\end{array}
\end{aligned}
$$

Where $A_{660}, A_{645}$ and $A_{470}$ represent absorbance at 660 $\mathrm{nm}, 645 \mathrm{~nm}$ and $470 \mathrm{~nm}$, respectively.

Optimum conditions for carotenoid production: Based on highest production of carotenoids by C. vulgaris in various parameters and nutrient sources, the final growth medium and conditions used were as follows: potassium nitrate as a nitrogen source, potassium phosphate as phosphorous source with $0.04 \mathrm{M}$ salinity. The concentration of $\mathrm{KNO}_{3}$ was $6 \mathrm{mM}$ whereas it was $0.8 \mathrm{mM}$ and $1.6 \mathrm{mM}$ for $\mathrm{K}_{2} \mathrm{HPO}_{4}$ and $\mathrm{KH}_{2} \mathrm{PO}_{4}$ respectively. The optimal $\mathrm{pH}$ was 8 and the microalgae were cultured at $35^{\circ} \mathrm{C}$ with a light intensity of 160 $\mu \mathrm{E} \backslash \mathrm{m}^{2} \backslash \mathrm{sec}$ for a period or 12 days

HPLC conditions and peak identification: Highperformance liquid chromatography (HPLC) analysis was performed using 1260 infinity series LC system installed with a G1311C pump, a G1329B autosampler and a G13166 column compartment and G4212B DAD detector. Chromatographic separation was carried out on a Zorbax Eclipse Plus C18 Analytical column (4.6 $\times$ $150 \mathrm{~mm}, 5 \mu$; Agilent Technologies). The mobile phase used was methanol: MTBE $(60: 40 \mathrm{v} / \mathrm{v})$ with the flow rate of $0.6 \mathrm{ml} / \mathrm{min}$ in the column at ambient temperature with an infusion volume of $20 \mu \mathrm{l}$ in each experiment. Injection volume was $20 \mu \mathrm{l}$ and detection was by UV absorbance at $450 \mathrm{~nm}$. Stock standard solutions were prepared by accurately adding $20 \mathrm{mg} / \mathrm{l}$ each of $\beta$ carotene, lutein, lycopene in MTBE and methanol. A calibration curve in the range $0-10 \mathrm{mg} / \mathrm{l}$ was set up, where the sample was diluted in the mobile phase. The samples from $C$. vulgaris was analyzed directly by dissolving in ethanol: MTBE (40:60). Various carotenoids were identified by comparing the retention times and absorption spectra of unknown peaks with reference standards. For calibration, a stock solution of $\beta$ carotene, lutein and astaxanthin were prepared by dissolving $10 \mathrm{mg}$ in $33.3 \mathrm{ml}$ of MTBE, $1 \mathrm{mg}$ in $3.3 \mathrm{ml}$ of MTBE and $10 \mathrm{mg}$ in 33.3. $\mathrm{ml}$ of DMSO, respectively.

$\boldsymbol{\beta}$-carotene extraction from $\boldsymbol{C}$. vulgaris: $\beta$-carotene from $C$. vulgaris was extracted by centrifuging the cells at $6000 \mathrm{rpm}$ for 10 mins and the pellet was washed with distilled water followed by lyophilization. Dried biomass was suspended in $75 \%$ acetone, vortexed until a white precipitate appeared. The sample was mixed with $\mathrm{KOH}(100 \mu \mathrm{l})$, vortexed and centrifuged. The supernatant was diluted in acetone and the mixture was allowed to stand until the two phases had clearly separated. The upper layer containing $\beta$ carotene was collected, evaporated to dryness using nitrogen purging (Wellburn and Lichtenthaler, 1984).

Lutein extraction from $C$. vulgaris: Lutein was extracted by performing consecutive extraction cycles using ethanol and the total lutein content was gravimetrically quantified after the complete removal of the solvent (Molino et al., 2020). After evaporating the solvent completely, saponification was carried out, adding $0.05 \mathrm{M} \mathrm{NaOH}$ solution in methanol $(1 \mathrm{ml})$ to the algal extract $(5 \mathrm{ml})$. This solution was left in the dark in an inert atmosphere for $7 \mathrm{~h}$ and the sample was neutralized using $0.05 \mathrm{M} \mathrm{NH}_{4} \mathrm{Cl}$ solution in methanol $(3 \mathrm{ml})$.

Astaxanthin extraction from C. vulgaris: Astaxanthin in the microalgae was extracted by centrifuging the cells and the pellet was disrupted in mortar and pestle. Dichloromethane $(10 \mathrm{ml})$ was added to the disrupted cells and the extraction was repeated until the cells were colourless. The solvent was evaporated in a 
rotary evaporator and saponified (Taucher et al., 2016) using acetone $(2.25 \mathrm{ml})$, methanol $(0.25 \mathrm{ml})$ and 0.05 $\mathrm{M} \mathrm{NaOH}$ in methanol $(0.5 \mathrm{ml})$. This was followed by the addition of petroleum ether $(3 \mathrm{ml})$, washing with $10 \% \mathrm{NaCl}(3 \mathrm{ml})$ and centrifugation for 2 mins at 5500 rpm. The upper phase was washed twice with $\mathrm{NaCl}$ and the organic phase was evaporated. Finally, the extracted astaxanthin was dissolved in $3 \mathrm{ml}$ of solvent (methanol, MTBE, water, 8:89:3, v/v).

Quantification of carotenoids: The extracts were eluted at a flow rate of $1 \mathrm{ml} / \mathrm{min}$, and the carotenoids content was detected by measuring absorbance at the wavelength range of $220-750 \mathrm{~nm}$. The maximal absorbance was chosen for quantification of carotenoid extracts (Berman et al., 2015; Harasym and Oledzki, 2014; Zhang et al., 2015; Gayathri et al., 2016). Accordingly, the extinction coefficient $\left(E^{1 \%}\right.$ cm $)$ was 2,273 at $450 \mathrm{~nm}, 3450$ at $476 \mathrm{~nm}$ and 2589 at $450 \mathrm{~nm}$ for $\beta$ carotene, astaxanthin and lutein, respectively (Eq.4).

$A \times \vee(\mathrm{ml}) \times$ dilution factor

Concentration of carotenoids $=$

$$
\text { ( } \mu \mathrm{g} / \mathrm{g} \text { of sample) } \quad \varepsilon \times W(\mathrm{~g})
$$

where $\mathrm{A}=$ absorbance, $\mathrm{V}=$ volume of extract in milliliters, $\varepsilon=$ extinction coefficient, and $W=$ dry weight of sample.

\section{RESULTS AND DISCUSSION}

Carotenoids are essential nutrients for human health in which $\beta$-carotene, lutein and astaxanthin derived
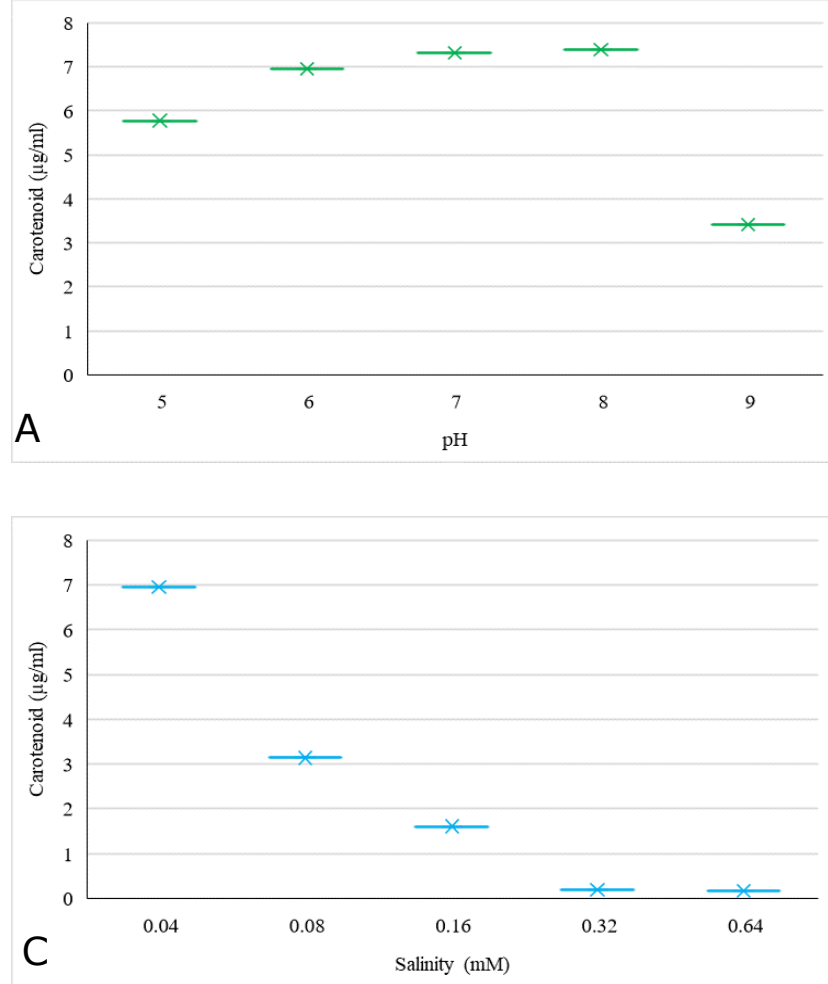

from microalgae are reported to have potential biological activities. $\beta$-carotene serves as a precursor for vitamin $A$ and reduces cardiovascular disease and certain cancers (Johnson, 2002). Lutein is the important pigment in the retina (Roberts et al., 2009) and astaxanthin is the nutrient supplement (Ambati et al., 2014). Reports are available, suggesting that culture conditions affect carotenoid production in chlorophyceae species (Benavente-Vald et al., 2016; Begum et al., 2016; Khan et al., 2018). Huang et al. (2018) characterized Chlorella zofingiensis to accumulate high amounts of carotenoid under various culture conditions. In this study, Culturing temperature, $\mathrm{pH}$, salinity, luminosity and nutrient type influenced $C$. vulgaris metabolism to accumulate carotenoids. The present results of carotenoid production under varying $\mathrm{pH}$, temperature, salinity and light intensity are depicted in Fig.1 (A-D). Carotenoid content was highest at $35^{\circ} \mathrm{C}$ with $7.11 \mu \mathrm{g} / \mathrm{ml}$ and was $7.39 \mu \mathrm{g} / \mathrm{ml}$ at $\mathrm{pH} 8$. Carotenoid biosynthesis enzymes are controlled by temperature and high temperatures increase the nutrient uptake and carotenoid accumulation (Bhosale et al., 2004; Fernandez-Sevilla et al., 2010) while BenAmotz (1996) reported lower temperatures as favourable for the production of carotenoids in Haematococcus, Dunaliella, Murielopsis and Scenedesmus species.

The salinity of $0.04 \mathrm{mM}$ has resulted in highest carotenoid accumulation $(6.95 \mu \mathrm{g} / \mathrm{ml})$ and the optimum light intensity was $160 \mu \mathrm{E} / \mathrm{m}^{2} \backslash \mathrm{sec}$. Salt stress significantly
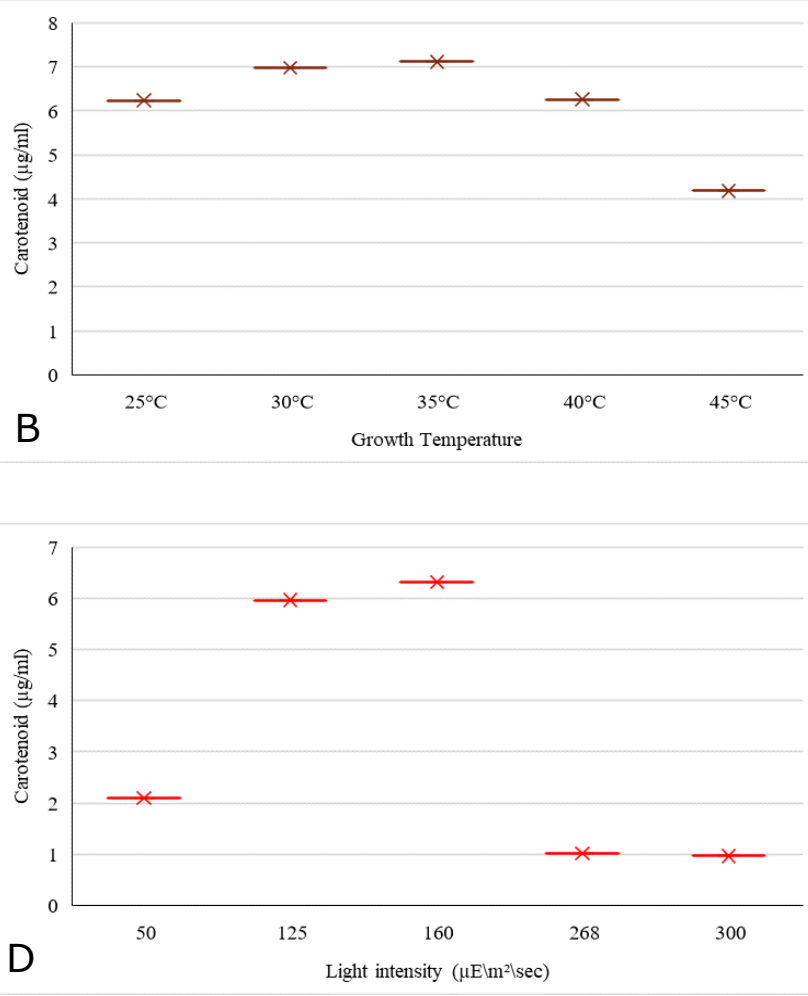

Fig. 1. Influence of Growth conditions on carotenoid content of C. vulgaris $(A) p H(B)$ Temperature (C) Salinity (D) Light intensity. 

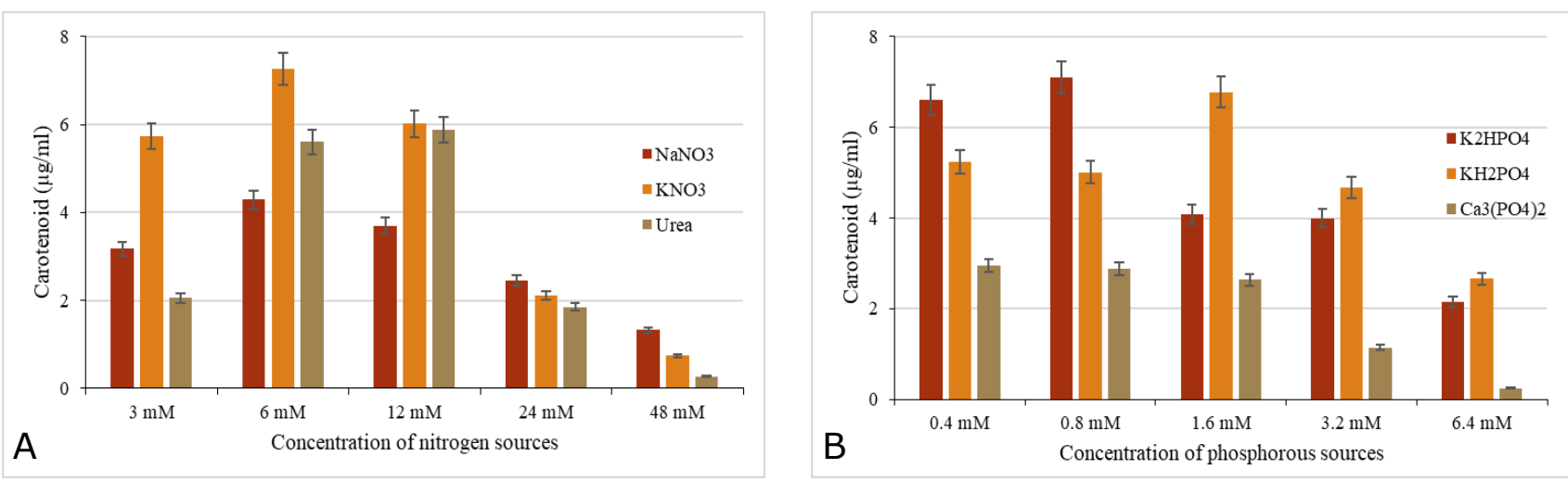

Fig. 2. Influence of nutrient sources on carotenoid content of C. vulgaris. (A) Nitrogen sources, (B) Phosphorous sources.

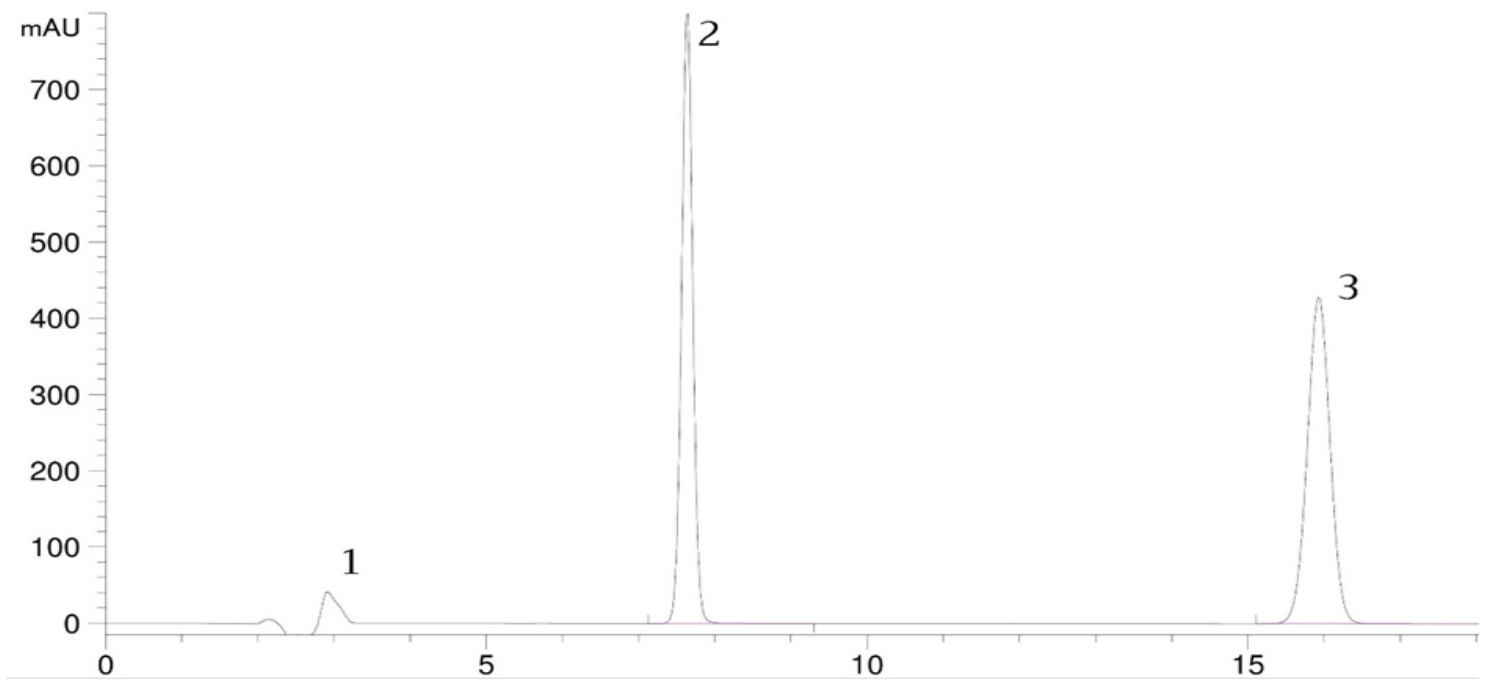

Fig. 3. HPLC profile of carotenoid standards. Peaks were identified as astaxanthin (1), lutein (2) and $\beta$-carotene (3).

increases the accumulation of secondary carotenoids in C. zofingiensis (Pelah et al., 2004). Another important factor affecting carotenoid production in microalgae is light intensity (Xie et al., 2013) as cell division slows down and cell lysis occurs under strong light. Photosynthetic machinery damages when there is excess light whereas insufficient light supply limits photosynthesis. Gayathri et al., (2020) indicated $200 \mu \mathrm{mol}$ m ${ }^{-2} S^{-1}$ was suitable for lutein production by $C$. salina.

Nutrient limitation leads to the accumulations of carotenoids as they affect the growth of microalgae and altering the photoprotective pigments. Among the nitrogen sources tested, both $\mathrm{KNO}_{3}$ and urea increased carotenoid content in C. vulgaris when the concentration was increased up to $12 \mathrm{mM}$. However, the addition of $\mathrm{KNO}_{3}$ to the growth medium at a concentration of $6 \mathrm{mM}$ resulted in $7.26 \mu \mathrm{g} / \mathrm{ml}$ (Fig.2 A and B). Minyuk et al., (2020) confirmed the replacement of nitrates with urea had increased astaxanthin by $C$. zofingiensis. Adding $\mathrm{K}_{2} \mathrm{HPO}_{4}$ and $\mathrm{KH}_{2} \mathrm{PO}_{4}$ increased carotenoid production while $\mathrm{Ca}_{3}\left(\mathrm{PO}_{4}\right)_{2}$ had little impact on carotenoid accumulation. Based on the highest carotenoid production under varying culture conditions, the growth media and conditions were optimized for C. vulgaris to improve carotenoids accumulation. $\beta$-carotene, lutein and astaxanthin were extracted from C. vulgaris and identified by HPLC (Fig. 3 and 4) to utilize $C$. vulgaris for the production of carotenoids of biological importance. From the HPLC chromatogram, lutein $(8.8 \%)$ was present in highest concentration followed by astaxanthin (4.6\%) and $\beta$-carotene $(3.9 \%)$. Microalgae are a good source of $\beta$-carotene and can be an alternate source for chemically synthesized $\beta$-carotene (Garcia-Gonzalez et al., 2005; Kleinegris et al., 2011). C. protothecoides has high productivity of lutein (Wei et al., 2008) while C. emersonii (Malis et al., 1993) and C. zofingiensis (Pelah et al., 2004) are able to astaxanthin.

\section{Conclusion}

Increasing demand for natural, health-protecting bioactive molecules has driven the research to explore alternate natural resources for carotenoid production. Exploration of regional microalgae for sustainable production of carotenoids is required as wild microalgae harvesting may have a negative ecological impact. Carotenoids derived microalgae are mostly from marine species, and this study attempted to produce $\beta$ carotene along with astaxanthin and lutein by freshwater C. vulgaris. Further, this study indicated that carot- 


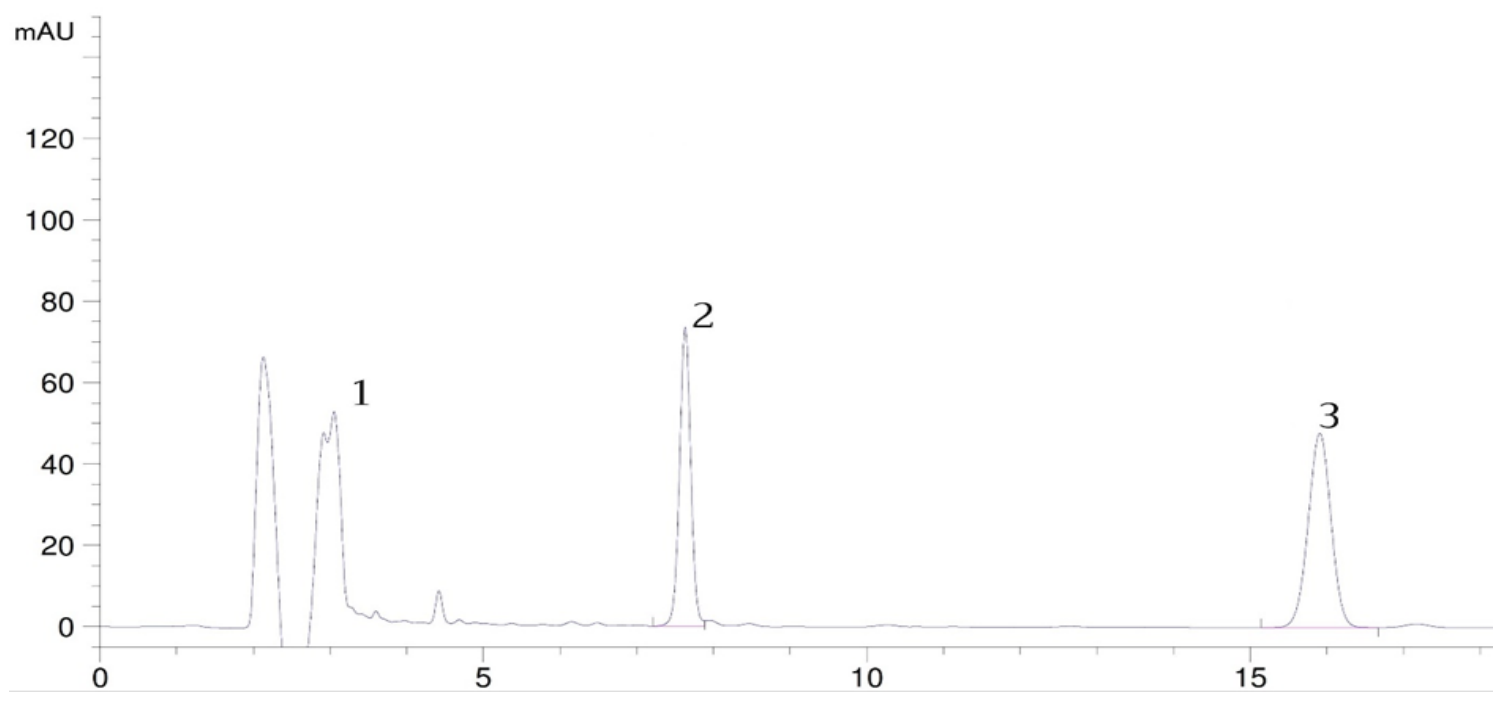

Fig. 4. HPLC profile of carotenoid samples from C. vulgaris.

enoid production by C. vulgaris could be enhanced by manipulating culture conditions, thereby attain desirable carotenoid production.

\section{Conflict of interest}

The authors declare that they have no conflict of interest.

\section{REFERENCES}

1. Ambati, R.R., Phang, S.M., Ravi, S. and Aswathanarayana, R.G. (2014). Astaxanthin: sources, extraction, stability, biological activities and its commercial applications - a review. Mar Drugs, 12(1): 128-152. DOI: 10.3390/ md12010128

2. Begum, H., Yusoff, F.M., Banerjee, S., Khatoon, H. and Shariff, M. (2016). Availability and utilization of pigments from microalgae. Crit Rev Food Sci Nutr., 56: 2209-2222. DOI: 10.1080/10408398.2013.7 64841.

3. Ben-Amotz, A. (1996). Effect of low temperature on the stereoisomer composition of b-carotene in the halotolerant alga, Dunaliella bardawil (Chlorophyta), J Phycol., 32: 272-275. DOI: 10.1111/j.0022-3646.1996.00272.x

4. Benavente-Vald, J.R., Aguilar, C., Contreras-Esquivel, J.C., Mendez-Zavala, A. and Montanez, J. (2016). Strategies to enhance the production of photosynthetic pigments and lipids in chlorophycae species. Biotechnology Reports. 10: 117-125. DOI: 10.1016/j.btre.2016.04.001

5. Berman, J., Zorrilla-Lopez, U., Farre, G., Zhu, C., Sandmann, G., Twyman, R.M, Capell, T. and Christou, P. (2015). Nutritionally important carotenoids as consumer products. Phytochem Rev., 14: 727-743. DOI: 10.1007/ s11101-014-9373-1

6. Bhosale, P. (2004). Environmental and cultural stimulants in the production of carotenoids from microorganisms. Appl Microbiol Biotechnol., 63: 351-361. DOI: 10.1007/ s00253-003-1441-1

7. Cha, K.H., Koo, S.Y. and Lee, D.U. (2008). Antiproliferative effects of carotenoids extracted from Chlorella ellipsoidea and Chlorella vulgaris on human colon cancer cells. J Agric Food Chem., 56: 10521-10526. DOI: 10.1021/jf802111x

8. Chuyen, H.V. and Eun, J.B. (2017). Marine carotenoids: Bioactivities and potential benefits to human health. Crit
Rev Food Sci Nutr., 57: 2600-2610. DOI: 10.1080/10408398.2015.1063477

9. Fernandez-Sevilla, J.M.J.M., Acien Fernandez, F.G. and Molina Grima, E. (2010). Biotechnological production of lutein and its applications. Appl Microbiol Biotechnol., 86: 27-40. DOI: 10.1007/s00253-009-2420-y

10.Garcia-Gonzalez, M., Moreno, J., Manzano, J.C., Florencio, F.J. and Guerrero, M.G. (2005). Production of Dunaliella salina biomass rich in 9-cis-beta-carotene and lutein in a closed tubular photobioreactor. J Biotechnol., 115(1): 81-90. DOI: 10.1016/j.jbiotec.2004.07.010

11.Gayathri, S., Rajasree S.R.R., Kirubagaran, R., Aranganathan, L. and Suman, T.Y. (2016) Spectral characterization of $\beta, \varepsilon$-carotene-3, 3'- diol (lutein) from marine microalgae Chlorella salina. Renewable Energy. 98: 78-83. DOI: 10.1016/j.renene.2016.04.065

12.Gayathri, S., Rajasree, S.R.R., Suman, T.Y., Aranganathan, L., Thriuganasambandam, R. and Narendrakumar, G. (2020). Induction of $\beta, \varepsilon$-carotene-3, 3'-diol (lutein) production in green algae Chlorella salina with airlift photobioreactor: interaction of different aeration and light-related strategies. Biomass Conv Bioref., DOI: 10.1007/s13399-019-00580-5

13.Guerin, M., Huntley, M.E. and Olaizola, M. (2003). Haematococcus astaxanthin: applications for human health and nutrition. Trends Biotechnol., 21: 210-216. DOI: 10.1016/ S0167-7799(03)00078-7

14.Harasym, J., and Oledzki, R. (2014). Effect of fruit and vegetable antioxidants on total antioxidant capacity of blood plasma. Nutrition., 30: 511-517. DOI: 10.1016/ j.nut.2013.08.019

15.Huang, W., Lin, Y., He, M., Gong, Y. and Huang, J. (2018). Induced High-Yield Production of Zeaxanthin, Lutein, and $\beta$-Carotene by a mutant of Chlorella zofingiensis. J Agric Food Chem., 66(4): 891-897. DOI: 10.1021/acs.jafc. $7 \mathrm{~b} 05400$

16.Johnson, E.J. (2002). The role of carotenoids in human health. Nutr Clin Care., 5: 56-65. DOI: 10.1046/j.15235408.2002.00004.x

17.Khan, I.M., Shin, H.J. and Kim D.J. (2018). The promising future of microalgae: current status, challenges, and optimization of a sustainable and renewable industry for biofuels, feed, and other products. Microb Cell Fact., 17: 36. DOI: $10.1186 / s 12934-018-0879-x$ 
18.Kleinegris, D.M., Janssen, M., Brandenburg, W.A. and Wijffels, R.H. (2011). Continuous production of carotenoids from Dunaliella salina. Enzyme Microb Technol., 48 (3): 253-259. DOI: 10.1016/j.enzmictec.2010.11.005

19.Li, J., Zhu, D., Niu, J., Shen, S. and Wang, G. (2011). An economic assessment of astaxanthin production by large scale cultivation of Haematococcus pluvialis. Biotechnol Adv., 29: 568-574. DOI: 10.1016/j.biotechad v.20 11.04.001

20.Lichtenthaler, H.K. and Buschmann, C. (2001). Chlorophylls and carotenoids: Measurements and characterization by UV-VIS spectroscopy. Current Protocols in Food Analytical Chemistry. 1(1): F4.3.1-F4.3.8. DOI: 10.1002/0471142913.faf0403s01

21.Malis, S.A., Cohen, E. and Ben Amotz, A. (1993). Accumulation of canthaxanthin in Chlorella emersonii. Physiologia Plantarum., 87: 232-236. DOI: 10.1111/j.13993054.1993.tb00148.x

22.Manayi, A., Abdollahi, M., Raman, T., Nabavi, S.F., Habtemariam, S., Daglia, M. and Nabavi, S.M. (2015). Lutein and cataract: from bench to bedside. Crit Rev Biotechnol., 8551: 1-11. DOI: 10.3109/07388551.2015.1049510

23.Mimuro, M. and Akimoto, S. (2003). Carotenoids of light harvesting systems: energy transfer processes from fucoxanthin and peridinin to chlorophyll Photosynthesis in Algae, Springer, Netherlands, Dordrecht. pp. 335-349. DOI: 10.1007/978-94-007-1038-2_15

24.Minyuk, G., Sidorov, R. and Solovchenko, A. (2020). Effect of nitrogen source on the growth, lipid, and valuable carotenoid production in the green microalga Chromochloris zofingiensis. J Appl Phycol. 32: 923935. DOI: 10.1007/s10811-020-02060-0

25.Mokashi, K., Shetty, V., George, S.A. and Sibi, G. (2016). Sodium bicarbonate as inorganic carbon source for higher biomass and lipid production integrated carbon capture in Chlorella vulgaris. Achievements in the Life Sciences. 10: 111-117. DOI: 10.1016/j.als.2016.05.011

26.Molino, A., Mehariya, S., lovine, A., Casella, P., Marino, T., Karatza, D., Chianese, S. and Musmarra, D. (2020). Enhancing biomass and lutein production from Scenedesmus almeriensis: Effect of carbon dioxide concentration and culture medium. Fron Plant Sci., 11: 415. DOI: $10.3389 /$ fpls. 2020.00415

27.Mulders, K.J.M. Lamers, P.P.., Martens, D.E. and Wijffels, R.H. (2014). Phototrophic pigment production with microalgae: biological constraints and opportunities. J Phycol., 50: 229-242. DOI: 10.1111/jpy.12173
28.Pelah, D., Sintov, A. and Cohen, E. (2004). The effect of salt stress on the production of canthaxanthin and astaxanthin by Chlorella zofingiensis grown under limited light intensity. World Journal of Microbiology and Biotechnology, 20: 483-486. DOI: 10.1023/b:wibi.0000040398.9 3103.21

29.Raposo, M.F.J., De Morais, A.M.M.B. and De Morais, R.M.S.C. (2015). Carotenoids from marine microalgae: A valuable natural source for the prevention of chronic diseases. Mar Drugs., 13: 5128-5155. DOI: 10.3390/ md13085128

30.Roberts, R.L., Green, J. and Lewis, B. (2009). Lutein and zeaxanthin in eye and skin health. Clin Dermatol. 27: 195201. DOI: $10.1016 /$ j.clindermatol.2008.01.011

31.Shi, X.M. and Chen, F. (1997). Stability of lutein under various storage conditions. Molecular Nutrition. Food Research. 41: 38-41. DOI:10.1002/food.19970410110

32.Taucher, J., Baer, S., Schwerna, P., Hofmann, D., Hummer, M., Buchholz, R. and Becker, A. (2016). Cell Disruption and pressurized liquid extraction of carotenoids from microalgae. J Thermodyn Catal., 7: 158. DOI: 10.4172/2158-7544.1000158

33.Wei, D., Chen, F., Chen, G., Zhang, X., Liu, L. and Zhang, H. (2008). Enhanced production of lutein in heterotrophic Chlorella protothecoides by oxidative stress. Sci China C Life Sci., 51: 1088-1093. DOI: 10.1007/ s11427-008-0145-2

34.Wellburn, A. and Lichtenthaler, H. (1984). Formulae and Program to Determine Total Carotenoids and Chlorophylls $A$ and B of Leaf Extracts in Different Solvents. In: Sybesma C. (eds) Advances in Photosynthesis Research. Advances in Agricultural Biotechnology, vol 2. Springer, Dordrecht. DOI: 10.1007/978-94-017-6368-4_3

35.Xie, Y., Ho, S.H., Chen, C.N.N., Chen, C.Y., Ng, I.S., Jing, K.J., Chang, J.S. and Lu, Y., (2013). Phototrophic cultivation of a thermo-tolerant Desmodesmus sp. for lutein production: Effects of nitrate concentration, light intensity and fed-batch operation. Bioresour Technol., 144: 435-444. DOI: 10.1016/j.biortech.2013.06.064

36.Zhang, D., Wan, M., del Rio-Chanona, E.A., Huang, J., Wang, W., Li, Y. and Vassiliadis, V.S., (2015). Dynamic modelling of Haematococcus pluvialis photoinduction for astaxanthin production in both attached and suspended photobioreactors. Algal Res., 13: 69-78. DOI: 10.1016/ j.algal.2015.11.019 